\title{
In Vitro Anti-Inflammatory Effect of Salvia sagittata Ethanolic Extract on Primary Cultures of Porcine Aortic Endothelial Cells
}

\author{
Irvin Tubon $\mathbb{D}^{1},{ }^{1,2,3}$ Augusta Zannoni $\mathbb{D}^{1},{ }^{1}$ Chiara Bernardini $\mathbb{D}^{1},{ }^{1}$ Roberta Salaroli, ${ }^{1}$ \\ Martina Bertocchi ${ }^{D}{ }^{1}$ Roberto Mandrioli $\left(\mathbb{D},{ }^{4}\right.$ Diego Vinueza $\left(\mathbb{D},{ }^{2}\right.$ Fabiana Antognoni ${ }^{1},{ }^{4}$ \\ and Monica Forni $\mathbb{D}^{1}$ \\ ${ }^{1}$ Department of Veterinary Medical Sciences-DIMEVET, University of Bologna, Ozzano dell'Emilia Bologna 40064, Italy \\ ${ }^{2}$ Escuela de Bioquimica y Farmacia, Facultad de Ciencias, Escuela Superior Politecnica de Chimborazo, Riobamba, \\ EC060155, Ecuador \\ ${ }^{3}$ Escuela de Enfermeria, Facultad de Ciencias Medicas, Universidad Regional Autónoma de Los Andes UNIANDES, Ambato, \\ EC180150, Ecuador \\ ${ }^{4}$ Department for Life Quality Studies-QuVi, University of Bologna, Rimini 47921, Italy
}

Correspondence should be addressed to Fabiana Antognoni; fabiana.antognoni@unibo.it

Received 19 October 2018; Revised 10 January 2019; Accepted 12 February 2019; Published 9 May 2019

Guest Editor: Ayman M. Mahmoud

Copyright (c) 2019 Irvin Tubon et al. This is an open access article distributed under the Creative Commons Attribution License, which permits unrestricted use, distribution, and reproduction in any medium, provided the original work is properly cited.

\begin{abstract}
The aim of the present research was to study the effects of an ethanolic extract of Salvia sagittata Ruiz \& Pav (SSEE), an endemic Ecuadorian plant traditionally used to treat inflammation and different intestinal affections, on primary cultures of porcine aortic endothelial cells (pAECs). pAECs were cultured in the presence of different concentrations (1-200 $\mu \mathrm{g} / \mathrm{mL})$ of SSEE for $24 \mathrm{~h}$, and cytotoxicity was evaluated by the MTT assay. SSEE did not negatively affect cellular viability at any concentration tested. Cell cycle was analyzed and no significant change was observed. Then, the anti-inflammatory effects of SSEE on pAECs were analyzed using a lipopolysaccharide (LPS) as the inflammatory stimulus. Different markers involved in the inflammatory process, such as cytokines and protective molecules, were evaluated by real-time quantitative PCR and Western blot. SSEE showed the ability to restore pAEC physiological conditions reducing interleukin- 6 and increasing Heme Oxygenase- 1 protein levels. The phytochemical composition of SSEE was also evaluated via HPLC-DAD and spectrophotometric assays. The presence of different phenolic acids and flavonoids was revealed, with rosmarinic acid as the most abundant component. SSEE possesses an interesting antioxidant activity, as assessed through both the Oxygen Radical Absorbance Capacity (ORAC) and 2,2-diphenyl-1picrylhydrazyl (DPPH) assays. In conclusion, results suggest that SSEE is endowed with an in vitro anti-inflammatory effect. This represents the initial step in finding a possible scientific support for the traditional therapeutic use of this plant.
\end{abstract}

\section{Introduction}

In the last few years, researches aimed to scientifically define the effects of natural products have been growing, not only due to the increasing popularity of plant-based Traditional Medicine but also because it meets the primary health-care needs for the majority of the population in developing countries [1]. Moreover, a huge number of medicinal plants, still not investigated, are available worldwide. Currently, more than 20,000 plant species are used to treat several diseases and are considered as potential reservoirs for new drugs
[2]. Recent studies suggest that the historical ethnopharmacological uses of plant-based medicines can represent a useful preliminary screening tool in the field of drug discovery [3].

Ecuador is considered one of the countries with the largest biodiversity in the world. The flora of mainland Ecuador is extremely rich: an estimated total of 17,000 species have so far been recorded $[4,5]$ and more than 3,000 medicinal plants are used in different native communities living on the highlands of the Ecuadorian Andes [6]. However, in most cases, the preparation, doses, and routes of administration of these herbal remedies are only 
transferred orally from generation to generation, while scientific information regarding their phytochemical or biological activity is insufficient or lacking [7].

Salvia L. (sage) is widely known as the largest genus in the Lamiaceae family, and to date, approximately 980 species have been recognized, most of which are restricted to the New World [8]. Some species of this genus have been used since ancient times as medicinal plants all around the world [911]. In addition, chemical constituents of various sage plants were described and comprise different terpenoids, several phenolic compounds, such as simple phenolics and caffeic acid derivatives, flavonoids as well as phenolic diterpenoids [12].

Salvia sagittata Ruiz \& Pav is an herbaceous perennial plant distributed in Ecuador and Peru. It has yellow-green arrow-shaped leaves and very sticky inflorescences in the apical part of the plant, formed by brilliant blue flowers with a prominent lower lip. Its leaves are commonly prepared either in an infusion to counteract different affections such as spasms, diarrhea, flatulence, fever, influenza, gastritis, stomach pain, cuts, and bumps or by heating with brandy and applying topically to treat rheumatism and articular pain [13-15]. Despite the ethnobotanical information in favor of multiple beneficial health effects of $S$. sagittata, scientific evidence from in vivo or in vitro studies is still lacking.

In order to test the possible biological activity of S. sagittata ethanolic extracts (SSEE), we used endothelial cells as a model system, given their fundamental role in different physiological processes. These cells are normally in dynamic equilibrium with their environment, preventing thrombus formation by the expression and secretion of anticoagulant, antiadhesive, and anti-inflammatory molecules. Nevertheless, in pathologic processes, such as inflammation, infection, or genetic alterations, endothelial cells change their phenotype from a resting to an active function that modulates the complement and coagulation cascades, thrombus formation, inflammation, and innate and adaptive immunity $[16,17]$. Endothelial cells are also recognized as key regulators of the inflammatory response controlling adhesion and migration of inflammatory cells as well as resolution of inflammation [18].

Tests were carried out on a primary culture instead of a cell line. Despite their viability and unlimited expansion, cell lines do not preserve various important markers and functions shown in vivo $[19,20]$. On the contrary, primary cells preserve most of these functions. Due to the biological similarities between swine and human at the anatomic [21], proteomic [22], and genomic level [23], primary cultures of porcine aortic endothelial cells have been used as a suitable in vitro model of human ones [24-26], as well as to test the anti-inflammatory activity of phytoextracts $[27,28]$.

In this context, we decided to evaluate SSEE for its phytochemical, antioxidant, and anti-inflammatory characteristics as related to biological activities in primary cultures of porcine aortic endothelial cells stimulated with a bacterial lipopolysaccharide.

\section{Materials and Methods}

2.1. Chemicals and Reagents. Human Endothelial Serum-Free Medium (hESFM), heat-inactivated fetal bovine serum (FBS), antibiotic-antimycotic, Dulbecco's phosphate-buffered saline (DPBS) and phosphate-buffered saline (PBS) were purchased from Gibco-Life Technologies (Carlsbad CA, USA), as previously described [27]. Propidium iodide (PI) was purchased from Miltenyi Biotec (Bergisch Gladbach, Germany). RNase A/T1 and the TRIzol reagent were purchased from Thermo Fisher Scientific (Waltham, MA, USA). RNA isolation was performed with a NucleoSpin RNA II kit (MACHEREYNAGEL GmbH \& Co. KG, Düren, Germany), and an iScript cDNA Synthesis Kit and iTaq Universal SYBR Green Supermix were used for cDNA synthesis and qPCR analysis, respectively (Bio-Rad Laboratories Inc., Hercules, CA, USA). 3-(4,5-Dimethylthiazol-2-yl)-2,5-diphenyltetrazolium bromide (MTT) was purchased from Sigma-Aldrich (St. Louis, Mo., USA). Folin-Ciocalteu's phenol reagent, 1,1-diphenyl-2picrylhydrazyl (DPPH), 6-hydroxyl-2,5,7,8-tetramethyl-chroman-2-carboxylic acid (Trolox), 2,2-Azobis(2-methylpropionamidine) dihydrochloride (AAPH), fluorescein, gallic acid, rutin, phenolic acids (4-hydroxybenzoic, caffeic, chlorogenic, ferulic, gallic, $p$-coumaric, synapic, syringic, transcinnamic, and rosmarinic acids), quercetin, quercetin-3-O-glucoside, quercetin-3-O-rhamnoside, quercetin-3-O-galactoside, kaempferol, kaempferol-3-O-rutinoside, hesperetin, hesperidin pure standards (>99.5\% purity) in powder form, and HPLC-grade solvents were purchased from Sigma-Aldrich. All standards were prepared as stock solutions at $1 \mathrm{mg} / \mathrm{mL}$ in methanol and stored in the dark at $-18^{\circ} \mathrm{C}$ for less than three months.

\subsection{Preparation of Plant Extract. Salvia sagittata Ruiz \& Pav} (SS) plants were collected, according to previous authorization of the Ministry of the Environment (N. 003-ICDPACH-MAE-2018-F), in Riobamba, Ecuador, on May 2016. The plants were identified and certified by Escuela Superior Politecnica de Chimborazo Herbarium, Riobamba, Ecuador, and a voucher specimen was deposited (N. 3342). Dried leaves ( $300 \mathrm{~g}$ ) were ground and extracted with $96 \%$ ethanol for $48 \mathrm{~h}$ at room temperature. After filtration, the solvent was evaporated using a rotary vacuum evaporator (Büchi, Ch-9230, Flawil, Switzerland) and dried in a vacuum at $40^{\circ} \mathrm{C}$ to obtain the ethanolic extract with a yield of $6.18 \%$. For experiments, the dry extract was dissolved in ethanol. The stock solution $(20 \mathrm{mg} / \mathrm{mL})$ was further used for HPLC analysis or diluted in culture media and membrane filtered by a $0.2 \mu \mathrm{m}$ Millipore filter (Millipore, Darmstadt, Germany).

2.3. Cell Culture and Treatments. Porcine aortic endothelial cells (pAECs) were isolated and maintained as previously described by Bernardini et al. [29]. Cells were seeded and routinely cultured in T25 tissue culture flasks $\left(4 \times 10^{5}\right.$ cells/flask) (T 25-Falcon, Becton-Dickinson, Franklin Lakes, NJ, USA). Successive experiments were conducted in 96-well plates (cell viability and anti-inflammatory test) or 24-well plates (qPCR and Western blot) (both by Becton-Dickinson) with confluent cultures. Cells were cultured in hESFM and added with 5\% FBS and $1 \mathrm{x}$ antimicrobial/antimycotic solution in a $5 \% \mathrm{CO}_{2}$ atmosphere at $38.5^{\circ} \mathrm{C}$.

The SSEE stock solution was diluted in the culture medium to obtain the desired concentrations $(1-200 \mu \mathrm{g} / \mathrm{mL})$ for cell exposure. Ethanol (1\%) was used as the vehicle. 
2.4. Cell Viability. Viability was determined using the MTT assay. Briefly, pAECs (sixth passage) were seeded in 96-well culture plates at a density of $3 \times 10^{3}$ cells/well and incubated for $24 \mathrm{~h}$. Then, the media were replaced with hESFM containing 5\% FBS and increasing SSEE doses (1, 10, 50, 100, and $200 \mu \mathrm{g} / \mathrm{mL}$ ) and incubated for another $24 \mathrm{~h}$ at $38.5^{\circ} \mathrm{C}$. Next, the MTT solution ( $5 \mathrm{mg} / \mathrm{mL}$ in PBS) was added to a final concentration of $0.5 \mathrm{mg} / \mathrm{mL}$ and then incubated for 2 $\mathrm{h}$ at $38.5^{\circ} \mathrm{C}$, followed by the addition of $0.1 \mathrm{~mL}$ MTT solubilisation solution. The formazan absorbance (Abs) was determined at $570 \mathrm{~nm}$, using Infinite ${ }^{\circledR}$ F50/Robotic absorbance microplate readers from TECAN Life Sciences (Männedorf, Switzerland).

2.5. Cell Cycle. The medium of pAEC confluence (sixth passage) was replaced with hESFM containing 5\% FBS and increasing SSEE doses $(1,10,50$, and $100 \mu \mathrm{g} / \mathrm{mL})$. After $24 \mathrm{~h}$, pAECs were harvested and washed once in $5 \mathrm{~mL}$ of PBS, and $1 \mathrm{~mL} / 10^{6}$ cells of $70 \%$ ice-cold ethanol was added drop by drop with continuous vortexing. The single cell suspension was fixed at $4^{\circ} \mathrm{C}$ for $24 \mathrm{~h}$. Then, the cells were washed with $10 \mathrm{~mL}$ of PBS, and the cellular pellet was treated with $1 \mathrm{~mL} / 10^{6}$ cells of staining solution containing PBS, $50 \mu \mathrm{g} / \mathrm{mL}$ of PI, and $100 \mu \mathrm{g} / \mathrm{mL}$ RNase A/T1 for $20 \mathrm{~min}$ in the dark at r.t. Cell distribution in cell cycle phases was analyzed by MACSQuant ${ }^{\circledR}$ Analyzer 10 and Flowlogic software (Miltenyi Biotec, Bergisch Gladbach, Germany). The Dean-Jett-Fox univariate model was used for this analysis.

2.6. In Vitro Tube Formation Assay. In vitro tube formation assay was performed as previously described [27]. Briefly, the experiments were carried out using an 8-slide-chamber glass (BD Falcon, Bedford, MA, USA) coated with an undiluted Geltrex ${ }^{\mathrm{TM}}$ LDEV-Free Reduced Growth Factor Basement Membrane Matrix. Firstly, the extracellular matrix coating was carried out $1 \mathrm{~h}$ before the seeding in a humidified incubator, at $38.5^{\circ} \mathrm{C}$ and $5 \% \mathrm{CO}_{2}$. Then pAECs (seventh passage) $\left(8 \times 10^{4}\right.$ cells/well $)$ were seeded with increasing SSEE doses $(1,10,25,50$, and $100 \mu \mathrm{g} / \mathrm{mL})$ for $18 \mathrm{~h}$.

At the end of the experimental time, images were acquired using a digital camera installed on a Nikon contrast phase microscope (Nikon, Yokohama, Japan) and analyzed by open software ImageJ 64.

2.7. Cell Viability after LPS Treatment. Briefly, pAECs (sixth passage) were seeded in 96-well culture plates at a density of $3 \times 10^{3}$ cells/well and incubated for $24 \mathrm{~h}$, then exposed to different SSEE concentrations $(1,10$, and $100 \mu \mathrm{g} / \mathrm{mL})$ in the presence of LPS $(25 \mu \mathrm{g} / \mathrm{mL})$ and incubated for another $24 \mathrm{~h}$ at $38.5^{\circ} \mathrm{C}$.

The MTT solution was added to a final concentration of $0.5 \mathrm{mg} / \mathrm{mL}$ and then incubated for $2 \mathrm{~h}$ at $38.5^{\circ} \mathrm{C}$ followed by the addition of $0.1 \mathrm{~mL}$ of dimethyl sulfoxide to dissolve the MTT-formazan. The amount of MTT-formazan was then determined by measuring Abs at $570 \mathrm{~nm}$.

2.8. Quantitative Real-Time PCR for IL-6, IL-8, and HO-1. pAECs (seventh passage) were seeded in a 24-well plate (approximately $4 \times 10^{4}$ cells/well), incubated until confluence, and then exposed to different concentrations of SSEE
$(1,10$, and $100 \mu \mathrm{g} / \mathrm{mL})$ in the absence or presence of LPS $(25 \mu \mathrm{g} / \mathrm{mL})$. RNA extraction was performed using the TRIzol reagent and NucleoSpin RNA II kit. After $24 \mathrm{~h}$, the cells were harvested and lysed using $1 \mathrm{~mL}$ TRIzol reagent and mixed by vortex ( $3 \mathrm{~min}$ ), and then, $200 \mu \mathrm{L}$ of chloroform was added to the suspension and mixed well. After incubation at room temperature $(10 \mathrm{~min})$, the samples were centrifuged (12000 $\mathrm{g}$ for $10 \mathrm{~min}$ ) and the aqueous phase was recovered. An equal volume of absolute ethanol (99\%) was added, and the resulting solution was applied to the NucleoSpin RNA Column. RNA was then purified according to the manufacturer's instructions. After spectrophotometric quantification, total RNA (250 ng) was reverse-transcripted to cDNA using the iScript cDNA Synthesis Kit in a final volume of $20 \mu \mathrm{L}$.

Swine primers were designed using Beacon Designer 2.07 (PREMIER Biosoft International, Palo Alto, CA, USA). Primer sequences, expected PCR product lengths, and accession numbers in the NCBI database are shown in Table 1.

To evaluate gene expression profiles, the quantitative real-time PCR (qPCR) was performed in a CFX96 thermal cycler (Bio-Rad) using a multiplex real-time reaction for reference genes (glyceraldehyde-3-phosphate dehydrogenase, GAPDH; hypoxanthine phosphoribosyltransferase, HPRT; $\beta$-Actin, $\beta$-ACT) and using TaqMan probes and SYBR green detection for the target genes (interleukin-6, IL-6; interleukin-8, IL-8; Heme Oxygenase-1, HO-1). All amplification reactions were performed in $20 \mu \mathrm{L}$ and analyzed in duplicates (10 $\mu \mathrm{L} /$ well). The multiplex PCR contained the following: $10 \mu \mathrm{L}$ of iTaqMan Probes Supermix (Bio-Rad), $1 \mu \mathrm{L}$ of forward and reverse primers ( $5 \mu \mathrm{M}$ each) of each reference gene, $0.8 \mu \mathrm{L}$ of iTaqMan probes $(5 \mu \mathrm{M})$ of each reference gene, $2 \mu \mathrm{L}$ of $\mathrm{cDNA}$, and $2.6 \mu \mathrm{L}$ of water. The following temperature profiling was used: initial denaturation at $95^{\circ} \mathrm{C}$ for 30 seconds followed by 40 cycles of $95^{\circ} \mathrm{C}$ for 5 seconds and $60^{\circ} \mathrm{C}$ for 30 seconds.

The SYBR Green reaction contained the following: $10 \mu \mathrm{L}$ of iQ SYBR Green Supermix (Bio-Rad), $0.8 \mu \mathrm{L}$ of forward and reverse primers ( $5 \mu \mathrm{M}$ each) of each target gene, $2 \mu \mathrm{L}$ of cDNA, and $7.2 \mu \mathrm{L}$ of water. The real-time program included an initial denaturation period of $1.5 \mathrm{~min}$ at $95^{\circ} \mathrm{C}$, 40 cycles at $95^{\circ} \mathrm{C}$ for $15 \mathrm{~s}$, and $60^{\circ} \mathrm{C}$ for $30 \mathrm{~s}$, followed by a melting step with ramping from $55^{\circ} \mathrm{C}$ to $95^{\circ} \mathrm{C}$ at a rate of $0.5^{\circ} \mathrm{C} / 10 \mathrm{~s}$.

The specificity of the amplified PCR products was confirmed by agarose gel electrophoresis and melting curve analysis.

The relative expressions of the studied genes were normalized based on the geometric mean of the three reference genes. The relative mRNA expression of the tested genes was evaluated as a fold of increase using the $2^{-\Delta \Delta C T}$ method [30] and referred to pAECs cultured under the standard condition (control).

2.9. Western Blot for HO-1. Western blot for HO-1 was performed as previously described [24]. Briefly, pAECs (seventh passage), treated in the same manner as mentioned above, were washed twice with ice-cold PBS, harvested, and lysed in SDS solution (Tris-HCl 50 mM; pH 6.8; SDS 2\%; glycerol $5 \%)$. After quantitative determination of the protein content 
TABLE 1: Primer sequences used for quantitative real-time polymerase chain reaction analysis.

\begin{tabular}{|c|c|c|c|c|}
\hline Gene & Sequence $\left(5^{\prime}-3^{\prime}\right)$ & $\begin{array}{l}\text { PCR product } \\
\text { (bp) }\end{array}$ & $\begin{array}{c}\text { GenBank accession } \\
\text { number }\end{array}$ & Reference \\
\hline HO-1 & $\begin{array}{l}\text { For: CGCTCCCGAATGAACAC } \\
\text { Rev: GCTCCTGCACCTCCTC }\end{array}$ & 112 & NM_001004027 & Bernardini et al. [31] \\
\hline IL-8 & $\begin{array}{l}\text { For: AGGACCAGAGCCAGGAAGAGAC } \\
\text { Rev: TGGAAAGGTGTGGAATGCGTATTTATG }\end{array}$ & 203 & AB057440.1 & Present study \\
\hline IL-6 & $\begin{array}{l}\text { For: AGCAAGGAGGTACTGGCAGAAAACAAC } \\
\text { Rev: GTGGTGATTCTCATCAAGCAGGTCTCC }\end{array}$ & 110 & AF518322.1 & Zannoni et al. [32] \\
\hline GAPDH & $\begin{array}{c}\text { For: ACATGGCCTCCAAGGAGTAAGA } \\
\text { Rev: GATCGAGTTGGGGCTGTGACT } \\
\text { Probe: HEX-CCACCAACCCCAGCAAGAGCACGC-BHQ1 }\end{array}$ & 106 & NM_001206359 & Duvigneau et al. [33] \\
\hline HPRT & $\begin{array}{c}\text { For: ATCATTATGCCGAGGATTTGGAAA } \\
\text { Rev: TGGCCTCCCATCTCTTTCATC } \\
\text { Probe: Tx-Red-CGAGCAAGCCGTTCAGTCCTGTCC-BQ2 }\end{array}$ & 102 & NM_001032376 & Present study \\
\hline$\beta$-ACT & $\begin{array}{c}\text { For: CTCGATCATGAAGTGCGACGT } \\
\text { Rev: GTGATCTCCTTCTGCATCCTGTC } \\
\text { Probe: FAM-ATCAGGAAGGACCTCTACGCCAACACGG-BHQ1 }\end{array}$ & 114 & KU672525.1 & Duvigneau et al. [33] \\
\hline
\end{tabular}

by a Protein Assay Kit (TP0300, Sigma-Aldrich), aliquots containing $20 \mu \mathrm{g}$ of proteins were separated on NuPAGE 4-12\% Bis-Tris gel for $45 \mathrm{~min}$ at $200 \mathrm{~V}$ and electrotransferred onto a nitrocellulose membrane. Blots were washed in PBS, and protein transfer was checked by staining the nitrocellulose membranes with $0.2 \%$ Ponceau S. After blocking the nonspecific binding with 5\% nonfat milk in PBS-T20 (PBS-0.1\% Tween-20) at room temperature for $1 \mathrm{~h}$, membranes were incubated with a 1:1000 dilution of anti-HO-1 rabbit polyclonal antibody (SPA-896, StressGen Biotechnologies Corp., Victoria, BC, Canada) overnight at $4^{\circ} \mathrm{C}$.

After several washings with PBS-T20, membranes were incubated with the secondary biotin-conjugate antibody and then with a $1: 1000$ dilution of an antibiotin horseradish peroxidase- (HRP-) linked antibody. The Western blots were developed using a chemiluminescent substrate (Clarity Western Substrate, Bio-Rad) according to the manufacturer's instructions. The intensity of the luminescent signal of the resultant bands was determined by the ChemiDoc Instrument using Lab Image Software (Bio-Rad).

In order to normalize the HO-1 data on the housekeeping protein, the membranes were stripped and reprobed for housekeeping $\beta$-tubulin (1:500 sc-5274 Santa Cruz Biotechnology Inc., Santa Cruz, CA, USA). The relative protein content (HO- $1 / \beta$-tubulin) was expressed as arbitrary units (AUs).

2.10. Antioxidant Activity Assays. Antioxidant activity (AA) of SSEE was measured by the ORAC and DPPH assays. The ORAC assay was performed in an automated plate reader (Victor 3, PerkinElmer, Turku, Finland) with 96-well plates, according to $\mathrm{Ou}$ et al. [34] with some modifications. All reagents were freshly prepared before the assay. In each well, $210 \mu \mathrm{L}$ of fluorescein $(10 \mathrm{nM})$ and $35 \mu \mathrm{L}$ of a sample, blank (10 mM phosphate buffer, $\mathrm{pH}$ 7.4), or standard (Trolox in the range $1-50 \mu \mathrm{M})$ were placed. The plate was heated to $37^{\circ} \mathrm{C}$ for $10 \mathrm{~min}$, and then, $35 \mu \mathrm{L}$ of AAPH $(240 \mathrm{mM})$ was added, immediately before beginning fluorescence (FL) measurement. Relative FL intensity was monitored at $1.5 \mathrm{~min}$ intervals until it was less than $5 \%$ of the initial reading value. Final ORAC values were calculated by using a regression equation between the Trolox concentration and the net area under the FL decay curve and were expressed as mmol Trolox equivalents per $g$ of extract or per $g$ of plant material (DW).

The DPPH assay was done according to the method of Brand-Williams et al. [35] with some modifications. A stock solution was prepared by dissolving $24 \mathrm{mg}$ DPPH with $100 \mathrm{~mL}$ methanol and then storing at $-20^{\circ} \mathrm{C}$ until needed. The working solution was prepared by mixing $10 \mathrm{~mL}$ stock solution with $45 \mathrm{~mL}$ methanol to obtain an Abs of $1.1 \pm$ 0.02 units at $515 \mathrm{~nm} .150 \mu \mathrm{L}$ of SSEE was allowed to react with $2850 \mu \mathrm{L}$ of the DPPH solution for $24 \mathrm{~h}$ in the dark. Abs measurements were carried out at $515 \mathrm{~nm}$. Results were determined from the regression equation of the Trolox calibration curve in the range of $25-500 \mu \mathrm{M}$ and expressed as mmol TE per $g$ of extract or per $g$ of plant material (DW).

2.11. Total Phenol Content and Total Flavonoid Content. Total Phenol Content (TPC) was determined using the Folin-Ciocalteu method [36]. $50 \mu \mathrm{L}$ of diluted extract was mixed with $250 \mu \mathrm{L}$ of a tenfold-diluted Folin-Ciocalteu phenol reagent. After $1 \mathrm{~min}, 800 \mu \mathrm{L}$ of $30 \%$ sodium carbonate solution was added to the mixture, shaken thoroughly, and diluted to $1.6 \mathrm{~mL}$ by adding $500 \mu \mathrm{L}$ of distilled water. The mixture was allowed to stand for $40 \mathrm{~min}$ at r.t., and the blue colour formed was measured at $700 \mathrm{~nm}$ using a UV-VIS spectrophotometer (V-630 Jasco, Jasco Europe S.r.l., Cremella, Italy). A calibration curve of gallic acid (ranging from 5 to $500 \mu \mathrm{g} / \mathrm{mL}$ ) was prepared, and the results, determined from the regression equation of the calibration curve, were expressed as mg of Gallic Acid Equivalents (GAE) per $\mathrm{g}$ of extract or per g of plant material (DW).

The total flavonoid content (TFC) was determined according to Zhishen et al. [37] with some modifications. $500 \mu \mathrm{L}$ of extract was diluted to $5 \mathrm{~mL}$ with distilled water, $300 \mu \mathrm{L}$ of $5 \% \mathrm{NaNO}_{2}$ was added, and the mixture was mixed 
well. After $5 \mathrm{~min}, 3 \mathrm{~mL}$ of a $10 \% \mathrm{AlCl}_{3}$ solution was added. After $6 \mathrm{~min}, 2 \mathrm{~mL}$ of a $1 \mathrm{M} \mathrm{NaOH}$ solution was added, and the total volume was made up to $10 \mathrm{~mL}$ with distilled water. Absorbance was measured against a blank at $510 \mathrm{~nm}$. Rutin was used as the standard for the calibration curve. TFC was calculated using the regression equation based on the calibration curve, and the results were expressed as mmol of Rutin Equivalents (RE) per g of extract or per $\mathrm{g}$ of plant material (DW).

2.12. HPLC-DAD Determination of Phenolic Acids and Flavonoids. HPLC-DAD determination of phenolic acids and flavonoids was performed as previously described [38]. $20 \mu \mathrm{L}$ of SSEE was injected into the HPLC system (Jasco Italy; PU-4180 pump, MD-4015 PDA detector, AS-4050 autosampler). The stationary phase was an Agilent (Santa Clara, CA, USA) ZORBAX Eclipse Plus C18 reversed-phase column $(100 \mathrm{~mm} \times 3 \mathrm{~mm}$ I.D., $3.5 \mu \mathrm{m})$. The chromatographic method for the analysis of phenolic acids was adapted from Mattila and Kumpulainen [39]. Gradient elution was carried out with a mixture of acidic phosphate buffer $(50 \mathrm{mM}, \mathrm{pH} 2.5)$ and acetonitrile flowing at $0.7 \mathrm{~mL} / \mathrm{min}$. Signals at 254, 280, and $329 \mathrm{~nm}$ were used for analyte quantitation. The recovery values of phenolic acids in spiked samples ranged from 78.8 to $92.2 \%$ (RSD $<9.8 \%$, $n=6$ ). The chromatographic method for the analysis of flavonoids was adapted from Wojdyło et al. [40]. Gradient elution was carried out with a mixture of $4.5 \%$ formic acid and acetonitrile. Runs were monitored at $280 \mathrm{~nm}$ for flavan-3-ols and $360 \mathrm{~nm}$ for flavonol glycosides. Retention times and spectra were compared with those of pure standards. Calibration curves were constructed for all standards at concentrations ranging from 1.0 to $100.0 \mathrm{ppm}\left(r^{2} \leq 0.9998\right)$. Results were expressed as $\mathrm{mg} / \mathrm{g}$ extract or per $\mathrm{g}$ of plant material (DW).

\section{Statistical Analysis}

Each treatment was replicated three or eight times (viability and anti-inflammatory tests) in three independent experiments. Data were analysed by a one-way analysis of variance (ANOVA) followed by the post hoc Tuckey comparison Test. Differences of at least $p<0.05$ were considered significant. Statistical analysis was carried out using GraphPad Prism 7 software.

\section{Results and Discussion}

4.1. Effect of SSEE on PAEC Viability and Angiogenesis. A large number of plants of the Ecuadorian flora are used for medicinal purposes. Nevertheless, scientific evidence supporting their use is still scarce. For this reason, a study was planned on the antiangiogenic and antioxidant activity and on phytochemical composition of Salvia sagittata, an endemic plant used in Ecuadorian Traditional Medicine. This choice was corroborated by the fact that several Salvia species were demonstrated to possess a protective effect against different external agents [40, 41].

Based on the traditional uses of the plant, it was decided to focus the biological tests on anti-inflammatory activity. A preliminary screening aimed at verifying the safety of SSEE was carried out. Treatment of pAECs with SSEE for $24 \mathrm{~h}$ did not negatively affect cell viability at any concentration tested (Figure 1(a)). Cells possessed a standard cell cycle for diploid cells (data not shown). Thus, SSEE does not seem to induce any cytotoxicity effect on pAECs in the concentration range examined. These results are in agreement with other researches in which different Salvia species did not affect cell viability [42]. After this preliminary assay, pAECs' angiogenesis was examined by an in vitro extracellular matrix-based assay. As a result, the capacity of cells to assemble a tube network formation was reduced after treatment with SSEE at 1, 10, 25, and $50 \mu \mathrm{g} / \mathrm{mL}$ (Figure 1(b) and Figure 1(c)).

\subsection{Effect of SSEE on LPS-Induced Cell Death and Cytokine} Expression. Inflammation and endothelial cells are closely related. In fact, in an inflammatory process, endothelial cells trigger the transcription of genes such as TNFR or TLR4 that activates the NF- $\kappa \mathrm{B}$ pathway and induces the expression of adhesive receptors (VCAM-1, E-selectin, and ICAM-1), procoagulant proteins (TF, PAI-1), cytokines, chemokines, and protective proteins [17]. Therefore, the anti-inflammatory activity of SSEE on pAECs was evaluated by an endothelial LPS inflammatory model $[27,28]$. Firstly, it was decided to assess a possible SSEE protective effect against LPS damage through a MTT assay. LPS exerted an evident cytotoxic effect, producing a significant $20 \%$ reduction of pAEC viability (Figure 2(a)) SSEE significantly reduced LPS-induced cytotoxicity, restoring the basal levels at $100 \mu \mathrm{g} / \mathrm{mL}$ concentration (Figure 2(a)).

Given the well-documented relationship between the inflammation process and oxidative stress [43], the in vitro antioxidant activity (AA) of the extract was evaluated by two assays, based on two different mechanisms: the ORAC assay, which is based on the hydrogen-atom transfer (HAT) mechanism, and the DPPH assay, which is an electron transfer assay. As it can be seen from Table 2, the AA values of the extract were rather similar in the two assays, being 0.10 and $0.11 \mathrm{mmol} \mathrm{TE} / \mathrm{g} \mathrm{DW}$, respectively. Even though it is extremely difficult to compare and to interpret data on the AA of plant extracts, due to the wide number of factors affecting the activity (extract preparation procedure, test method used, etc.), the values of the extract resulting from both the DPPH and ORAC assays were very close to those reported for other crude plant extracts prepared in a similar way [44].

The antioxidant activity and protective effect of SSEE against LPS might confirm its anti-inflammatory activity and justify the traditional Salvia sagittata uses. Nevertheless, to gain insight into the molecular mechanisms involved in mediating these responses, it was decided to investigate how SSEE could influence some of the main inflammatory markers and protective molecules expressed by endothelial cells at both the transcription and proteomic levels.

IL-6 and IL-8 are stress-responsive proinflammatory chemokines that play a pivotal role in the pathogenesis of different acute inflammatory conditions [44, 45]. They can be synthesized by different cell types; IL- 6 activates the differentiation of cytotoxic $\mathrm{T}$ cells and the monocyte and induces 


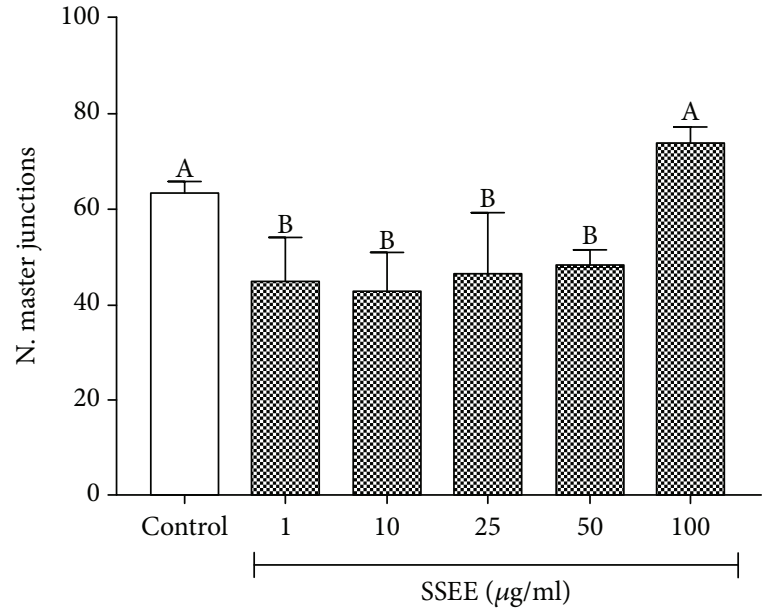

(b)
$6 \mathrm{~h}$
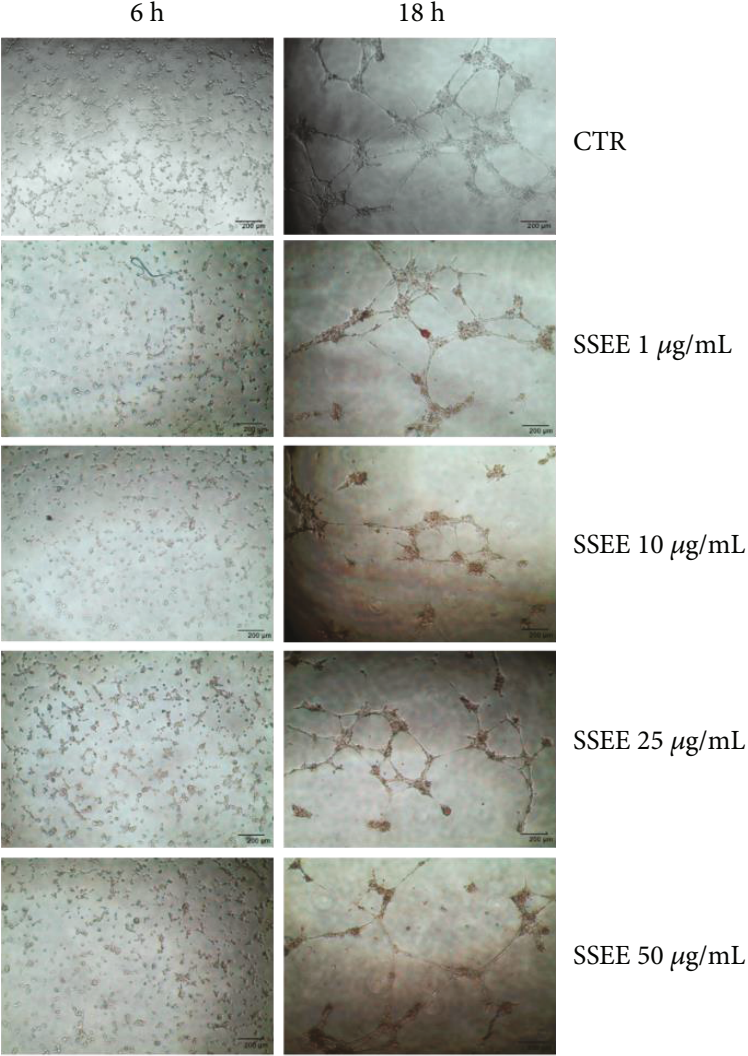

SSEE $50 \mu \mathrm{g} / \mathrm{mL}$
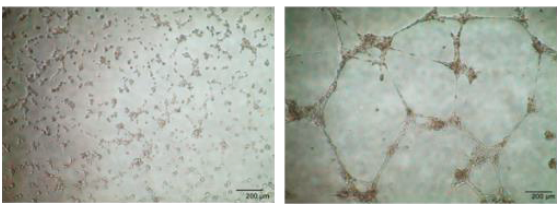

SSEE $100 \mu \mathrm{g} / \mathrm{mL}$

(c)

FIGURE 1: Effects of SSEE on pAEC physiology. Cells were treated with different concentrations of SSEE for (a) $24 \mathrm{~h}$ for cell viability and (b) $18 \mathrm{~h}$ for angiogenesis. Cell network formations were recorded at $6 \mathrm{~h}$ and $18 \mathrm{~h}$ after treatment (c). Data shown are representative of 8 (a) or 3 (b) replicates in at least three independent experiments. Each bar represents mean \pm S.D. Different letters above the bars indicate significant differences ( $p<0.05$, ANOVA, post hoc Tukey's test).

angiogenesis and increases vascular permeability [46, 47], while IL-8 is a potent leukocyte and fibroblast chemoattractant/activator and it is closely associated with endothelial permeability, inflammatory recruitment, and release of proinflammatory mediators [48].

As can be seen in Figures 2(b) and 2(c), LPS induced a significant increase of both the IL- 6 and the IL- 8 mRNA expression after $24 \mathrm{~h}$ of treatment. SSEE at all tested concentrations was able to revert the LPS-induced IL-6 gene expression increase (Figure 2(b)) and to revert that of IL-8 in the $1-10 \mu \mathrm{g} / \mathrm{mL}$ range (Figure $2(\mathrm{c})$ ).

This is in agreement with other in vivo and in vitro reports on other species of the Salvia genus. Yue et al. [49] have reported that $S$. miltiorrhiza induced a reduction of cytokine expression, thus alleviating liver inflammation. In a similar way, Gao et al. [50] have reported the reduction of nitric oxide, tumor necrosis factor (TNF- $\alpha$ ), and IL-6 secretion in RAW264.7 macrophages by a novel compound isolated from S. miltiorrhiza in a LPS inflammatory model.

4.3. Effect of SSEE on HO-1 Expression. In an inflammatory process, to avoid endothelial dysfunction, there is a tight balance between inflammatory and protective molecules. Recent findings indicated that HO-1, initially studied for its ability to degrade heme, is a key regulator molecule of endothelial cell function providing an important cellular defense mechanism against tissue injury [50, 51]. Moreover, during chronic inflammation, HO-1 performs a double function inhibiting leukocyte infiltration and promoting VEGF-driven noninflammatory angiogenesis that facilitates tissue repair [52]. For this reason, the HO-1 gene expression and protein level were evaluated by RT-PCR and Western blot, respectively. 


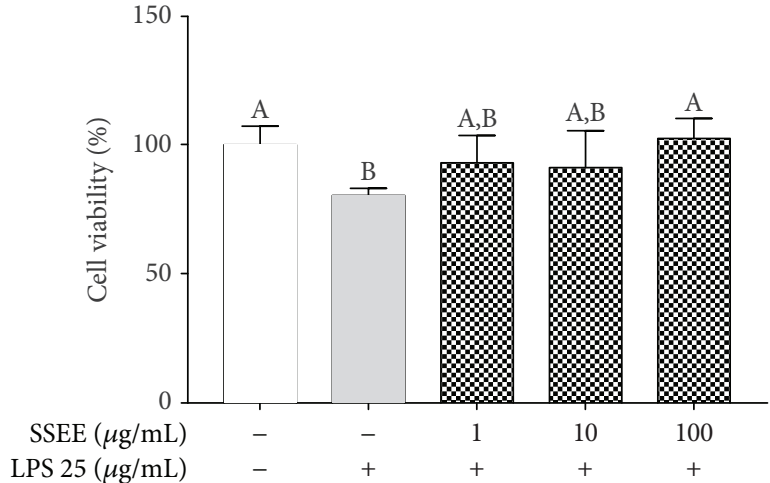

(a)

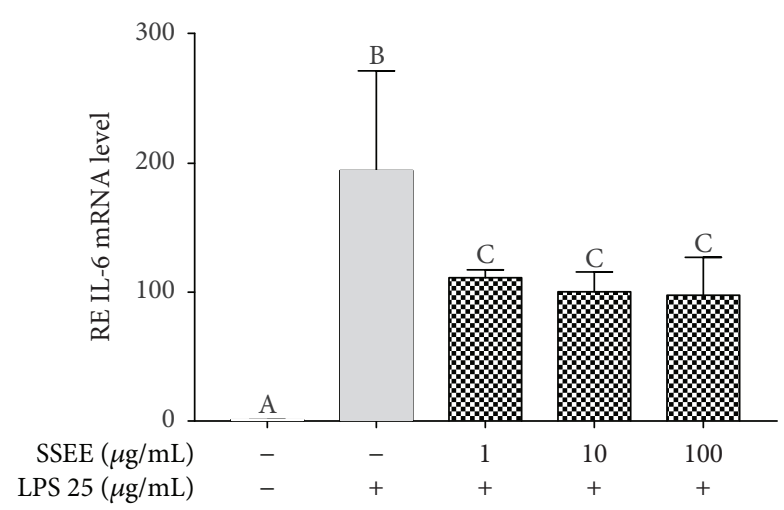

(b)

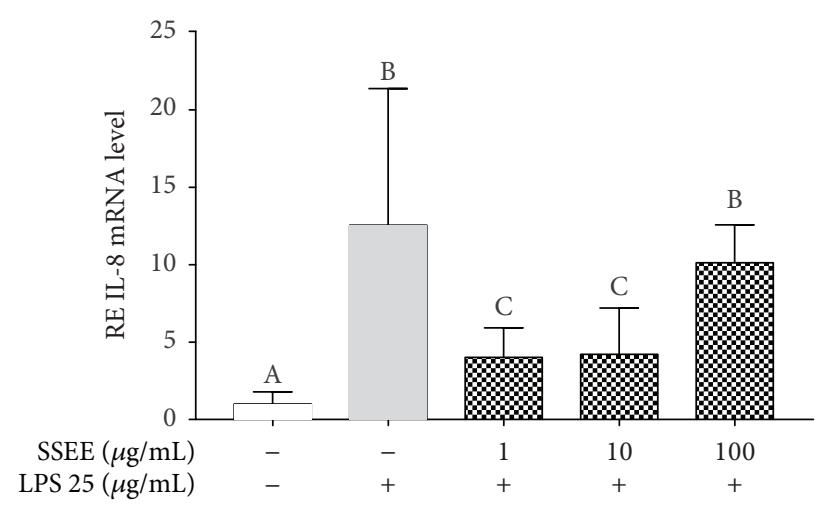

(c)

FIGURE 2: Effects of SSEE on LPS-induced pAEC damage. (a) Effect of SSEE on LPS-induced cytotoxicity. Each bar represents mean \pm S.D. Effect of SSEE on (b) IL-6 and (c) IL-8 mRNA expression. Relative expression (RE) was calculated as the fold of change with respect to the control cells, and the error bars represent the range of relative gene expression. Data shown are representative of at least three independent experiments. Different letters above the bars indicate significant differences ( $p<0.05$, ANOVA, post hoc Tukey's test).

TABle 2: Antioxidant activity (AA), TPC, TFC, phenolic acids, and flavonoid content (expressed as $\mathrm{mg} / \mathrm{g}$ ) in SSEE. Data are the mean \pm S.E. of three technical determinations.

\begin{tabular}{lcc}
\hline \multirow{2}{*}{ Assays or compounds } & \multicolumn{2}{c}{ Concentration referred to } \\
& Ethanolic plant extract & Plant dry weight \\
\hline AA & $1.85 \pm 0.15$ & $0.11 \pm 0.09$ \\
$\quad$ ORAC (mmol TE/g) & $1.57 \pm 0.11$ & $0.097 \pm 0.007$ \\
$\quad$ DPPH (mmol TE/g) & $164.95 \pm 8.57$ & $10.19 \pm 0.53$ \\
TPC & $109.13 \pm 5.23$ & $6.74 \pm 0.32$ \\
TFC & $84.76 \pm 9.32$ & $5.23 \pm 0.57$ \\
RA & $0.2 \pm 0.02$ & $0.012 \pm 0.001$ \\
HESP & $0.7 \pm 0.04$ & $0.043 \pm 0.004$ \\
Q-3-O-GLU & $1.32 \pm 0.16$ & $0.08 \pm 0.09$ \\
CHA & $0.17 \pm 0.02$ & $0.010 \pm 0.001$ \\
CA & $0.02 \pm 0.003$ & $0.001 \pm 0.0001$ \\
\hline
\end{tabular}

RA: rosmarinic acid; HESP: hesperetin; Q-3-O-GLU: quercetin-3-Oglucoside; CHA: chlorogenic acid; CA: caffeic acid; SA: syringic acid.
Compared to the control, the SSEE treatment at the highest tested level increased the HO-1 gene expression (Figure 3(a)); concerning the protein level, a clearer dosedependent response was observed (Figure 3(b)). Although LPS itself did induce an increase in HO-1 levels [29], upon SSEE treatment, the protein level was even higher, and this suggests a possible correlation with its anti-inflammatory properties towards interleukins.

4.4. Phytochemical Investigation of SSEE. Phytochemical investigation of the polyphenolic composition was done through both spectrophotometric assays and HPLC-DAD (Table 2). TPC and TFC suggest that SSEE was rich in polyphenols, and flavonoids represented more than $65 \%$ of polyphenol structures. TPC through the Folin-Ciocalteu procedure was investigated in a wide array of medicinal plants, and values ranging from 9 to $183 \mathrm{mg}$ GAE/g DW in plants belonging to different botanical families were reported. Considering the slight differences in the extract preparation and the different species investigated by these authors, the TPC content of the Salvia sagittata extract (10.19 mg GAE/g DW) turned out to be very close to that reported by Kähkönen et al. [53] for Thymus vulgaris methanolic extract $(9 \mathrm{mg}$ GAE/g DW). 


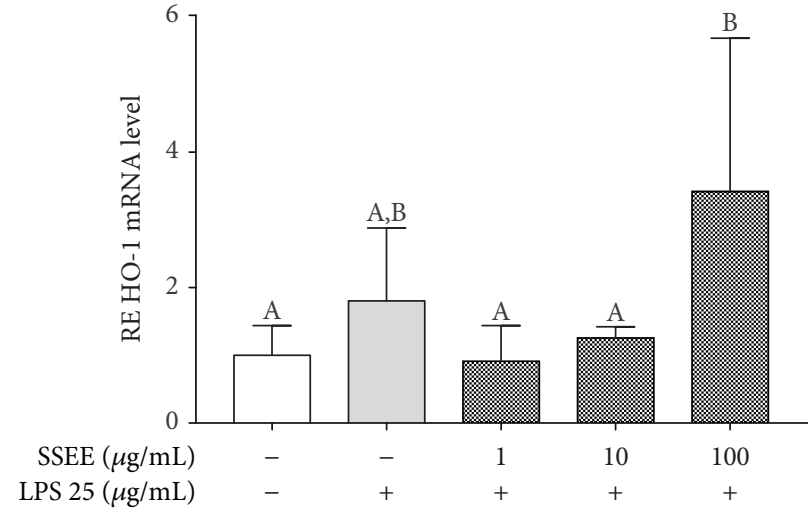

(a)

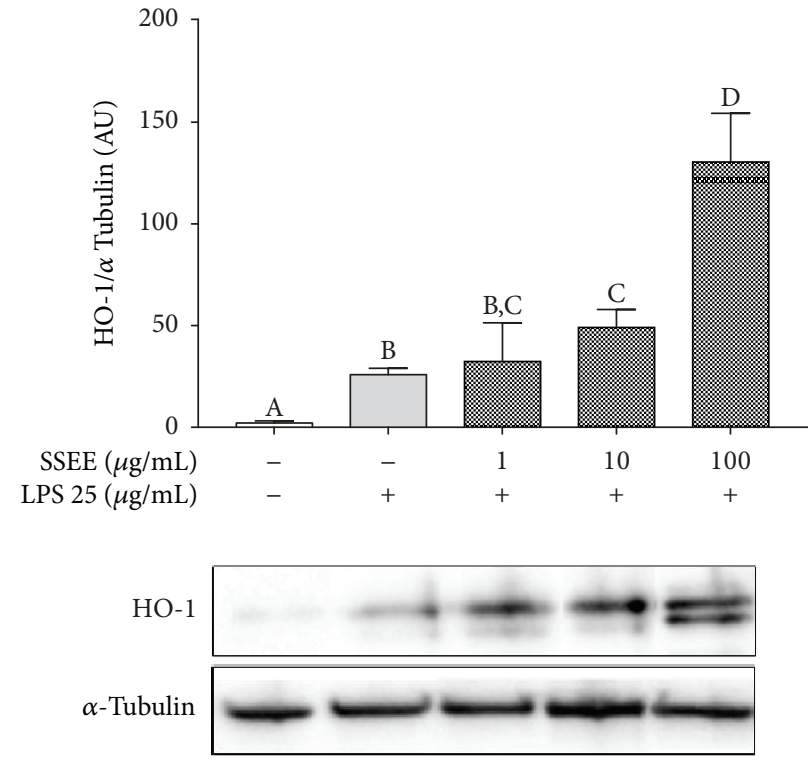

(b)

FIgURE 3: Effects of SSEE on the HO-1 expression in LPS-induced pAEC damage. (a) Expression of the HO-1 mRNA relative expression was calculated as the fold of change with respect to the control cells, and the error bar represents the range of relative expression. (b) Representative Western blot of HO-1 and relative housekeeping $\alpha$-tubulin. Data shown are representative of three replicates in at least three independent experiments. Each bar represents mean \pm S.D. Different letters above the bars indicate significant differences ( $p<0.05$, ANOVA, post hoc Tukey's test). AU: arbitrary unit.

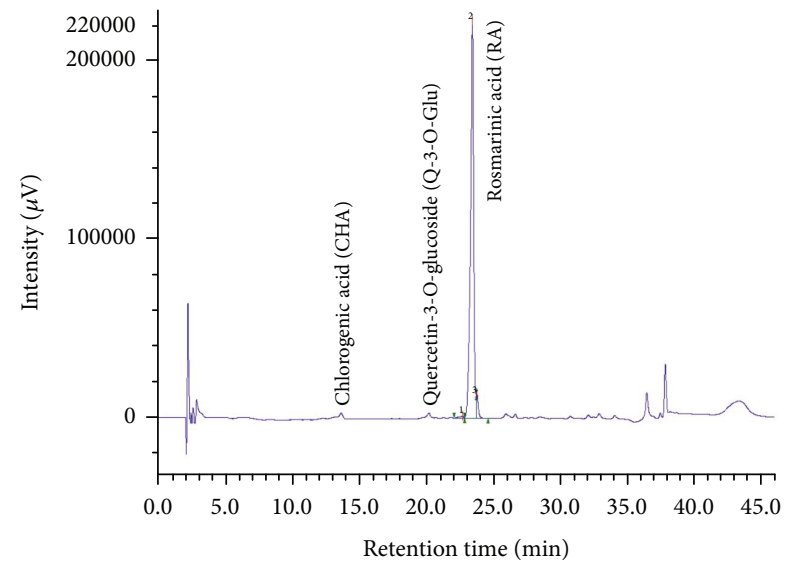

FIgUre 4: The HPLC profile of SSEE showing the main phenolic compounds identified.

HPLC-DAD analysis showed that the major phenolic acid-derivative compound in the extract was rosmarinic acid (RA) (Figure 4), reaching about $50 \%$ of TPC. Other phenolic compounds were, in decreasing order, chlorogenic acid, quercetin-3-O-glucoside, hesperetin, cinnamic acid, and syringic acid, the latter being present only in trace amounts (Table 2). These results are in agreement with a recent phytochemical screening carried out on three plant extracts belonging to the Lamiaceae family by Cocan et al. [54], which demonstrates that RA represents the major phenolic acid compound of an ethanolic extract from Salvia officinalis (L.) leaves.
RA has been previously demonstrated to exert antiinflammatory and antiangiogenic activity, and its mechanism of action has been deeply investigated both in vitro and in vivo. Huang and Zheng [55] reported that this phenolic compound reduced the $\mathrm{H}_{2} \mathrm{O}_{2}$-dependent VEGF expression and IL-8 release in human umbilical vein endothelial cells, as well as intracellular ROS levels. In human leukemia cells, RA treatment significantly sensitizes TNF- $\alpha$-induced apoptosis through the suppression of NF- $\kappa \mathrm{B}$ and ROS generation [56], and in a tumor-bearing mice model, a tumor growthsuppressing activity was demonstrated [57]. Thus, most biological activities of RA, including the neuroprotective [58] and hepatoprotective [59] ones, have been related to its marked antioxidant properties, deriving from its ability to act as a lipid peroxidation inhibitor and ROS scavenger [60].

Thus, it is possible to hypothesize that this cinnamic acid derivative gives the main contribution to the antiinflammatory effects of the ethanolic extract of Salvia sagittata observed in this study, although the role of other phenolic compounds, not identified in our analysis, cannot be excluded. Moreover, a synergistic action among all chemical components can also explain the biological activity of the extract.

In conclusion, the results obtained here represent the first evidence on phytochemical aspects and anti-inflammatory activity of the Salvia sagittata extract, which can justify the use of this plant in the Ecuadorian Traditional Medicine.

\section{Data Availability}

The original data used to support the findings of this study are available from the corresponding author upon request. 


\section{Disclosure}

Preliminary data has been presented as an oral presentation at the I Euroindoamerican Congress, 2018, Madrid, Spain, 29 May-1 June 2018.

\section{Conflicts of Interest}

The authors declare no conflict of interest.

\section{Acknowledgments}

The authors are grateful to the University of Bologna (Programma di Ricerca Fondamentale Orientata, RFO-MIUR 2017), the DIMEVET (BIR 2015-Bando Attrezzature for the contribution for the purchase of the "MACSQuant Analyzer 10"), and the Ecuadorian Secretary of Higher Education Science, Technology and Innovation (SENESCYT) for the governmental $\mathrm{PhD}$ scholarship. This research was developed under agreement MAE-DNB-CM-2018-0086.

\section{References}

[1] WHO, WHO Guidelines for Assessing Quality of Herbal Medicines with Reference to Contaminants and Residues, WHO Press, World Health Organization, Geneva, Switzerland, 2007.

[2] A. Shakeri, A. Sahebkar, and B. Javadi, "Melissa officinalis L. - a review of its traditional uses, phytochemistry and pharmacology," Journal of Ethnopharmacology, vol. 188, pp. 204-228, 2016.

[3] C. Gyllenhaal, M. R. Kadushin, B. Southavong et al., "Ethnobotanical approach versus random approach in the search for new bioactive compounds: support of a hypothesis," Pharmaceutical Biology, vol. 50, no. 1, pp. 30-41, 2012.

[4] G. Harling, "Current Scandinavian botanical research in Ecuador," Reports of the Botanical Institute from Aarhus University, Aarhus, Denmark, vol. 15, pp. 9-10, 1986.

[5] C. Ulloa Ulloa and D. Neill, Cinco años de adiciones a la flora del Ecuador 1999-2004, UTPL, Missouri Botanical Garden, Funbotanica, Editorial Universidad Técnica Particula de Loja, Loja, Ecuador, 2005.

[6] P. Jorgensen and S. León Yánez, "Catalogue of the vascular plants of Ecuador," in Monographs in Systematic Botany, Missouri Botanical Garden Press, St. Louis, MO, USA, 1999.

[7] P. Naranjo and R. Escaleras, La Medicina Tradicional en el Ecuador, Corporacion Editoral Nacional, Universidad Andina Simón Bolivar, Quito, 1995.

[8] J. B. Walker, K. J. Sytsma, J. Treutlein, and M. Wink, "Salvia (Lamiaceae) is not monophyletic: implications for the systematics, radiation, and ecological specializations of Salvia and tribe Mentheae," American Journal of Botany, vol. 91, no. 7, pp. 1115-1125, 2004.

[9] V. Cardile, A. Russo, C. Formisano et al., "Essential oils of Salvia bracteata and Salvia rubifolia from Lebanon: chemical composition, antimicrobial activity and inhibitory effect on human melanoma cells," Journal of Ethnopharmacology, vol. 126, no. 2, pp. 265-272, 2009.

[10] G. Tel, M. Öztürk, M. E. Duru, M. Harmandar, and G. Topçu, "Chemical composition of the essential oil and hexane extract of Salvia chionantha and their antioxidant and anticholinesterase activities," Food and Chemical Toxicology, vol. 48, no. 11, pp. 3189-3193, 2010.

[11] J.Xu, K. Wei, G. Zhang et al., "Ethnopharmacology, phytochemistry, and pharmacology of Chinese Salvia species: a review," Journal of Ethnopharmacology, vol. 225, pp. 18-30, 2018.

[12] Y. B. Wu, Z. Y. Ni, Q. W. Shi et al., "Constituents from salvia species and their biological activities," Chemical Reviews, vol. 112, no. 11, pp. 5967-6026, 2012.

[13] H. De-la-Cruz, G. Vilcapoma, and P. A. Zevallos, "Ethnobotanical study of medicinal plants used by the Andean people of Canta, Lima, Peru," Journal of Ethnopharmacology, vol. 111, no. 2, pp. 284-294, 2007.

[14] E. C. Fernandez, Y. E. Sandi, and L. Kokoska, "Ethnobotanical inventory of medicinal plants used in the Bustillo Province of the Potosi Department, Bolivia," Fitoterapia, vol. 74, no. 4, pp. 407-416, 2003.

[15] M. Gonzales De La Cruz, S. Baldeón Malpartida, H. Beltrán Santiago, V. Jullian, and G. Bourdy, "Hot and cold: medicinal plant uses in Quechua speaking communities in the high Andes (Callejón de Huaylas, Ancash, Perú)," Journal of Ethnopharmacology, vol. 155, no. 2, pp. 1093-1117, 2014.

[16] J. S. Pober and W. C. Sessa, "Evolving functions of endothelial cells in inflammation," Nature Reviews Immunology, vol. 7, no. 10, pp. 803-815, 2007.

[17] L. T. Roumenina, J. Rayes, M. Frimat, and V. FremeauxBacchi, "Endothelial cells: source, barrier, and target of defensive mediators," Immunological Reviews, vol. 274, no. 1, pp. 307-329, 2016.

[18] A. Kadl and N. Leitinger, "The role of endothelial cells in the resolution of acute inflammation," Antioxidants \& Redox Signaling, vol. 7, no. 11-12, pp. 1744-1754, 2005.

[19] C. Pan, C. Kumar, S. Bohl, U. Klingmueller, and M. Mann, "Comparative proteomic phenotyping of cell lines and primary cells to assess preservation of cell type-specific functions," Molecular \& Cellular Proteomics, vol. 8, no. 3, pp. 443-450, 2009.

[20] C. S. Alge, S. M. Hauck, S. G. Priglinger, A. Kampik, and M. Ueffing, "Differential protein profiling of primary versus immortalized human RPE cells identifies expression patterns associated with cytoskeletal remodeling and cell survival," Journal of Proteome Research, vol. 5, no. 4, pp. 862-878, 2006.

[21] H. Niemann and W. A. Kues, "Application of transgenesis in livestock for agriculture and biomedicine," Animal Reproduction Science, vol. 79, no. 3-4, pp. 291-317, 2003.

[22] A. M. de Almeida and E. Bendixen, "Pig proteomics: a review of a species in the crossroad between biomedical and food sciences," Journal of Proteomics, vol. 75, no. 14, pp. 4296-4314, 2012.

[23] A. L. Archibald, L. Bolund, C. Churcher et al., "Pig genome sequence - analysis and publication strategy," BMC Genomics, vol. 11, no. 1, p. 438, 2010.

[24] C. Bernardini, F. Greco, A. Zannoni, M. L. Bacci, E. Seren, and M. Forni, "Differential expression of nitric oxide synthases in porcine aortic endothelial cells during LPS-induced apoptosis," Journal of Inflammation, vol. 9, p. 47, 2012.

[25] C. Bernardini, A. Zannoni, M. L. Bacci, and M. Forni, "Protective effect of carbon monoxide pre-conditioning on LPSinduced endothelial cell stress," Cell Stress \& Chaperones, vol. 15, no. 2, pp. 219-224, 2010.

[26] G. Botelho, C. Bernardini, A. Zannoni, V. Ventrella, M. L. Bacci, and M. Forni, "Effect of tributyltin on mammalian 
endothelial cell integrity," Comparative Biochemistry and Physiology Part C: Toxicology \& Pharmacology, vol. 176-177, pp. 79-86, 2015.

[27] C. Bernardini, A. Zannoni, M. Bertocchi, I. Tubon, M. Fernandez, and M. Forni, "Water/ethanol extract of $\mathrm{Cucu}$ mis sativus L. fruit attenuates lipopolysaccharide-induced inflammatory response in endothelial cells," BMC Complementary and Alternative Medicine, vol. 18, no. 1, p. 194, 2018.

[28] M. Bertocchi, G. Isani, F. Medici et al., "Anti-inflammatory activity of Boswellia serrata extracts: an in vitro study on porcine aortic endothelial cells," Oxidative Medicine and Cellular Longevity, vol. 2018, Article ID 2504305, 9 pages, 2018.

[29] C. Bernardini, A. Zannoni, M. E. Turba et al., "Heat shock protein 70 , heat shock protein 32 , and vascular endothelial growth factor production and their effects on lipopolysaccharideinduced apoptosis in porcine aortic endothelial cells," Cell Stress \& Chaperones, vol. 10, no. 4, pp. 340-348, 2005.

[30] K. J. Livak and T. D. Schmittgen, "Analysis of relative gene expression data using real-time quantitative PCR and the 2 $-\Delta \Delta$ CT method," Methods, vol. 25, no. 4, pp. 402-408, 2001.

[31] C. Bernardini, P. Gaibani, A. Zannoni et al., "Treponema denticola alters cell vitality and induces HO-1 and Hsp70 expression in porcine aortic endothelial cells," Cell Stress \& Chaperones, vol. 15, no. 5, pp. 509-516, 2010.

[32] A. Zannoni, M. Giunti, C. Bernardini et al., "Procalcitonin gene expression after LPS stimulation in the porcine animal model," Research in Veterinary Science, vol. 93, no. 2, pp. 921-927, 2012.

[33] J. C. Duvigneau, R. T. Hartl, S. Groiss, and M. Gemeiner, "Quantitative simultaneous multiplex real-time PCR for the detection of porcine cytokines," Journal of Immunological Methods, vol. 306, no. 1-2, pp. 16-27, 2005.

[34] B. Ou, M. Hampsch-Woodill, and R. L. Prior, "Development and validation of an improved oxygen radical absorbance capacity assay using fluorescein as the fluorescent probe," Journal of Agricultural and Food Chemistry, vol. 49, no. 10, pp. 4619-4626, 2001.

[35] M. Brand-Williams, E. Cuvelier, and C. Berset, "Use of a free radical method to evaluate antioxidant activity," LWT - Food Science and Technology, vol. 28, no. 1, pp. 25-30, 1995.

[36] V. L. Singleton and J. A. Rossi, "Colorimetry of total phenolics with phosphomolybdic-phosphotungstic acid reagents," American Journal of Enology and Viticulture, vol. 16, no. 3, pp. 144-158, 1965.

[37] J. Zhishen, T. Mengcheng, and W. Jianming, "The determination of flavonoid contents in mulberry and their scavenging effects on superoxide radicals," Food Chemistry, vol. 64, no. 4, pp. 555-559, 1999.

[38] F. Antognoni, R. Mandrioli, A. Bordoni et al., "Integrated evaluation of the potential health benefits of Einkorn-based breads," Nutrients, vol. 9, no. 11, p. 1232, 2017.

[39] P. Mattila and J. Kumpulainen, "Determination of free and total phenolic acids in plant-derived foods by HPLC with diode-array detection," Journal of Agricultural and Food Chemistry, vol. 50, no. 13, pp. 3660-3667, 2002.

[40] A. Wojdyło, P. Nowicka, P. Laskowski, and J. Oszmiański, "Evaluation of sour cherry (Prunus cerasus L.) fruits for their polyphenol content, antioxidant properties, and nutritional components," Journal of Agricultural and Food Chemistry, vol. 62, no. 51, pp. 12332-12345, 2014.
[41] L.-N. Gao, K. Yan, Y.-L. Cui, G.-W. Fan, and Y.-F. Wang, "Protective effect of Salvia miltiorrhiza and Carthamus tinctorius extract against lipopolysaccharide-induced liver injury," World Journal of Gastroenterology, vol. 21, no. 30, pp. 90799092, 2015.

[42] M. Porres-Martínez, E. González-Burgos, M. E. Carretero, and M. P. Gómez-Serranillos, "Protective properties of Salvia lavandulifolia Vahl. essential oil against oxidative stressinduced neuronal injury," Food and Chemical Toxicology, vol. 80, pp. 154-162, 2015.

[43] U. Singh and I. Jialal, "Oxidative stress and atherosclerosis," Pathophysiology, vol. 13, no. 3, pp. 129-142, 2006.

[44] P. Stratil, B. Klejdus, and V. Kubáň, "Determination of total content of phenolic compounds and their antioxidant activity in vegetables - evaluation of spectrophotometric methods," Journal of Agricultural and Food Chemistry, vol. 54, no. 3, pp. 607-616, 2006.

[45] D. G. Remick, "Interleukin-8," Critical Care Medicine, vol. 33, pp. S466-S467, 2005.

[46] J. Scheller, A. Chalaris, D. Schmidt-Arras, and S. RoseJohn, "The pro- and anti-inflammatory properties of the cytokine interleukin-6," Biochimica et Biophysica Acta (BBA) - Molecular Cell Research, vol. 1813, no. 5, pp. 878-888, 2011.

[47] S. A. Jones, "Directing transition from innate to acquired immunity: defining a role for IL-6," Journal of Immunology, vol. 175, no. 6, pp. 3463-3468, 2005.

[48] H. Laursen, H. E. Jensen, P. S. Leifsson et al., "Immunohistochemical detection of interleukin-8 in inflamed porcine tissues," Veterinary Immunology and Immunopathology, vol. 159, no. 1-2, pp. 97-102, 2014.

[49] S. Yue, B. Hu, Z. Wang et al., "Salvia miltiorrhiza compounds protect the liver from acute injury by regulation of p38 and NF $\kappa$ B signaling in Kupffer cells," Pharmaceutical Biology, vol. 52, no. 10, pp. 1278-1285, 2014.

[50] H. Gao, W. Sun, J. Zhao et al., "Tanshinones and diethyl blechnics with anti-inflammatory and anti-cancer activities from Salvia miltiorrhiza Bunge (Danshen)," Scientific Reports, vol. 6, article 33720, 2016.

[51] C. F. Chang, X. M. Liu, K. J. Peyton, and W. Durante, "Heme oxygenase- 1 counteracts contrast media-induced endothelial cell dysfunction," Biochemical Pharmacology, vol. 87, no. 2, pp. 303-311, 2014.

[52] D. Calay and J. C. Mason, "The multifunctional role and therapeutic potential of HO-1 in the vascular endothelium," Antioxidants \& Redox Signaling, vol. 20, no. 11, pp. 17891809, 2014.

[53] M. P. Kähkönen, A. I. Hopia, H. J. Vuorela et al., "Antioxidant activity of plant extracts containing phenolic compounds," Journal of Agricultural and Food Chemistry, vol. 47, no. 10, pp. 3954-3962, 1999.

[54] I. Cocan, E. Alexa, C. Danciu et al., "Phytochemical screening and biological activity of Lamiaceae family plant extracts," Experimental and Therapeutic Medicine, vol. 15, no. 2, pp. 1863-1870, 2018.

[55] S. Huang and R. Zheng, "Rosmarinic acid inhibits angiogenesis and its mechanism of action in vitro," Cancer Letters, vol. 239, no. 2, pp. 271-280, 2006.

[56] D.-O. Moon, M.-O. Kim, J.-D. Lee, Y. H. Choi, and G.-Y. Kim, "Rosmarinic acid sensitizes cell death through suppression of TNF- $\alpha$-induced NF- $\kappa$ B activation and ROS generation in 
human leukemia U937 cells," Cancer Letters, vol. 288, no. 2, pp. 183-191, 2010.

[57] W. Cao, C. Hu, L. Wu, L. Xu, and W. Jiang, "Rosmarinic acid inhibits inflammation and angiogenesis of hepatocellular carcinoma by suppression of NF- $\kappa \mathrm{B}$ signaling in $\mathrm{H} 22$ tumorbearing mice," Journal of Pharmacological Sciences, vol. 132, no. 2, pp. 131-137, 2016.

[58] K. Ono, L. Li, Y. Takamura et al., "Phenolic compounds prevent amyloid $\beta$-protein oligomerization and synaptic dysfunction by site-specific binding," The Journal of Biological Chemistry, vol. 287, no. 18, pp. 14631-14643, 2012.

[59] R. Domitrović, M. Skoda, V. Vasiljev Marchesi, O. Cvijanović, E. Pernjak Pugel, and M. B. Stefan, "Rosmarinic acid ameliorates acute liver damage and fibrogenesis in carbon tetrachloride-intoxicated mice," Food and Chemical Toxicology, vol. 51, pp. 370-378, 2013.

[60] Y. Nakamura, Y. Ohto, A. Murakami, and H. Ohigashi, "Superoxide scavenging activity of rosmarinic acid from Perilla frutescens Britton Var. acuta f. viridis," Journal of Agricultural and Food Chemistry, vol. 46, no. 11, pp. 4545-4550, 1998. 


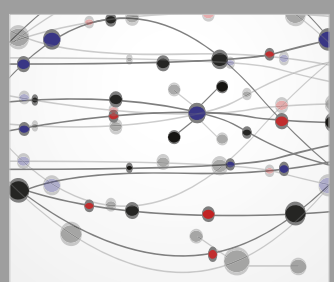

The Scientific World Journal
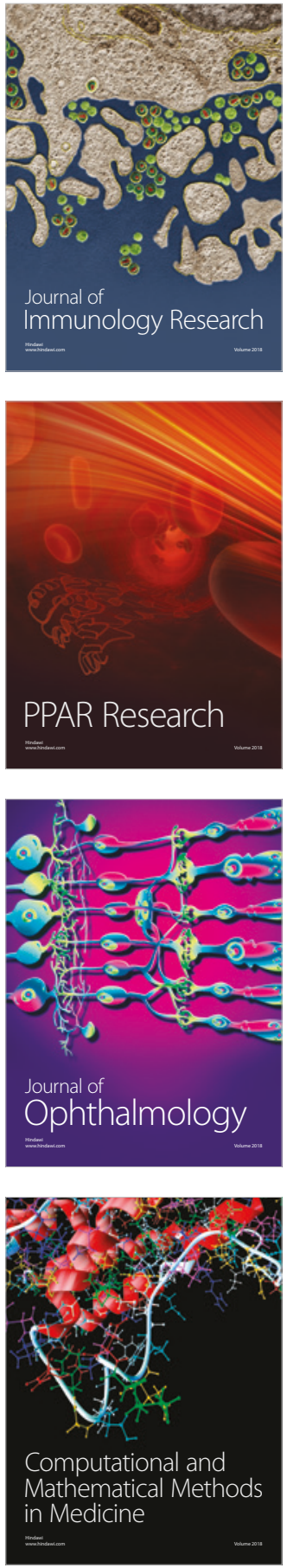

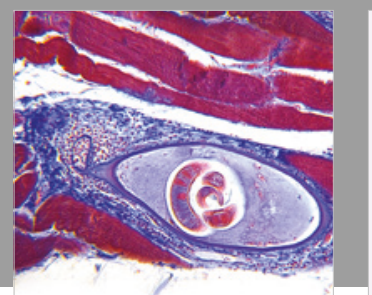

Gastroenterology Research and Practice

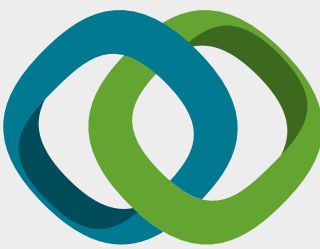

\section{Hindawi}

Submit your manuscripts at

www.hindawi.com
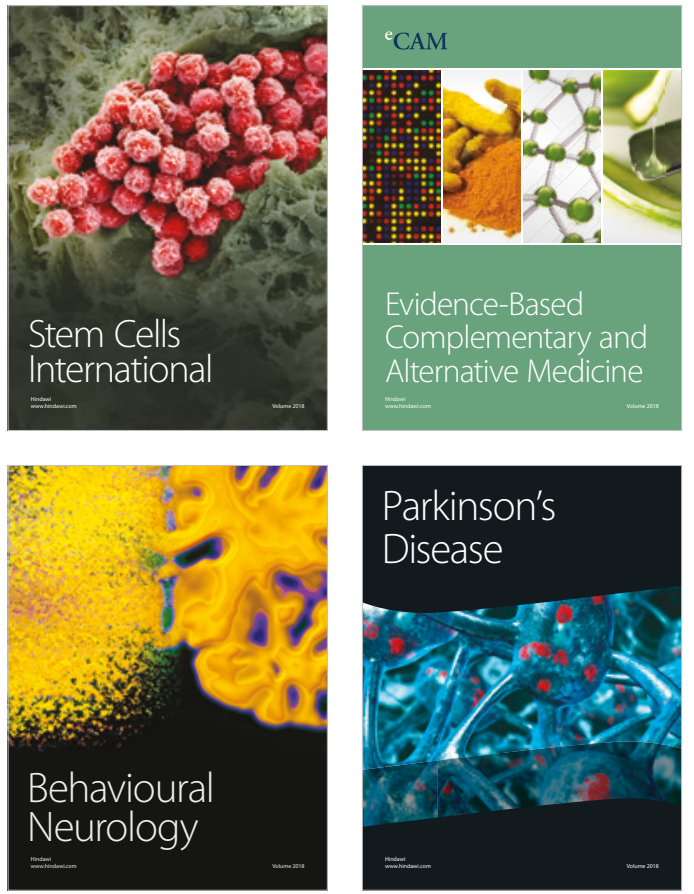

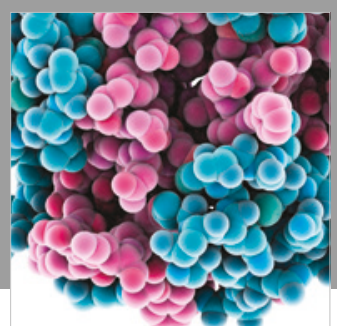

ournal of

Diabetes Research

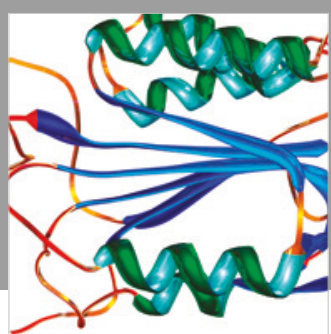

Disease Markers
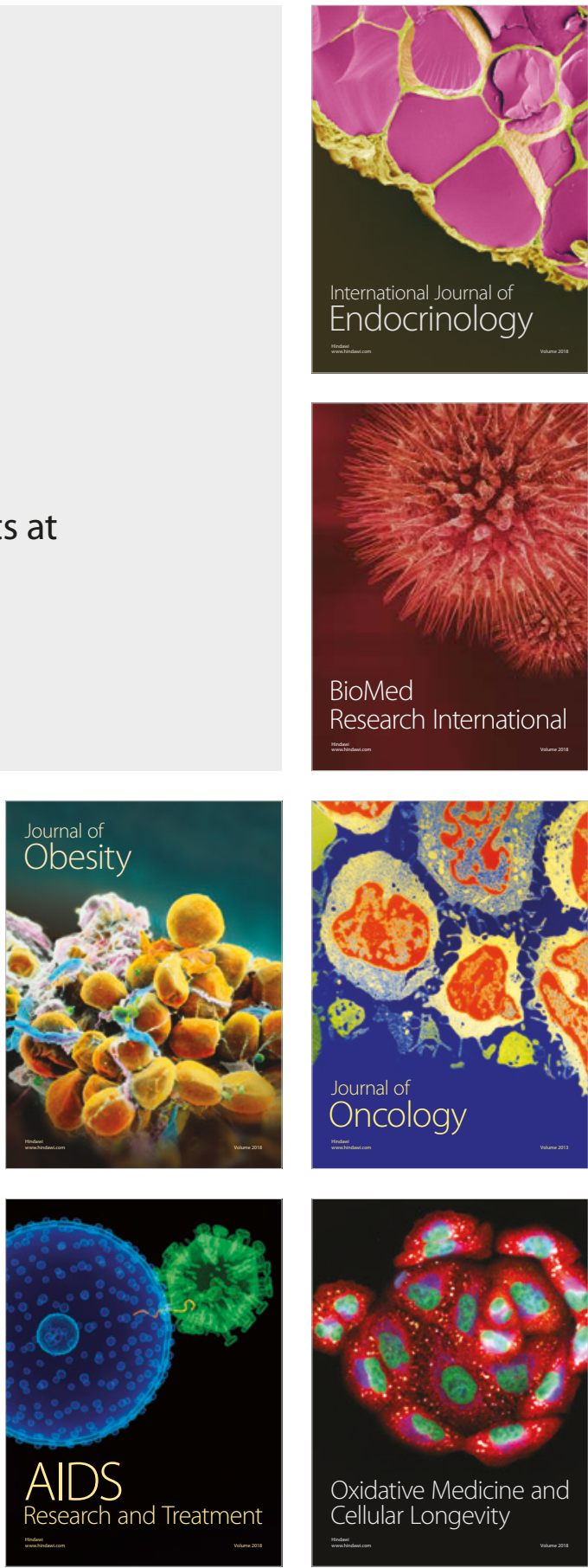